УДК $544.169 ; 544.25 ; 547.7+547.8 ; 542.06$

\title{
ЭФФЕКТИВНЫЙ ПРОГНОЗ КОЛОНЧАТОГО МЕЗОМОРФИЗМА У ДИСКОТИЧЕСКИХ, ЗВЕЗДООБРАЗНЫХ И ПОЛИКАТЕНАРНЫХ ОРГАНИЧЕСКИХ СОЕДИНЕНИЙ НА ОСНОВЕ РАСЧЕТА МОЛЕКУЛЯРНЫХ ПАРАМЕТРОВ
}

\author{
Акопова Ольга Борисовна \\ д.х.н., ст.н.с., старший научный сотрудник \\ Жарникова Наталия Валерьевна \\ к.х.н., старший научный сотрудник \\ Смирнова Антонина Игоревна \\ к.физ.-мат.н., ведущий научный сотрудник \\ Бумбина Наталья Вячеславовна \\ к.х.н., научный сотрудник \\ Усольцева Надежда Васильевна \\ д.х.н., проф., главный научный сотрудник \\ ФГБОУ ВО «Ивановский государственный университет»
}

Аннотация: Оценена возможность использования методики прогнозирования формирования колончатых мезофаз дискотическими, звездообразными и поликатенарными органическими соединениями с помощью компьютерного моделирования и последующего расчета молекулярных параметров в оригинальной программе “CMP ChemCard”. Осуществлен молекулярный дизайн потенциальных мезогенов с прогнозируемым типом мезоморфизма и синтезированы их отдельные представители. Обоснована эффективность применения разработанного метода для поиска новых молекулярных структур указанных типов, потенциально способных проявлять колончатый мезоморфизм.

Ключевые слова: жидкие кристаллы, колончатый мезоморфизм, моделирование, прогноз, дискотические, звездообразные, поликатенарные соединения, синтез. 


\title{
COLUMNAR MESOMORPHISM PREDICTION OF DISCOTIC, STAR-SHAPED AND POLYCATENAR ORGANIC COMPOUNDS BASED ON MOLECULAR PARAMETERS CALCULATION
}

\author{
Akopova Olga Borisovna \\ Zharnikova Nataliia Valeryevna \\ Smirnova Antonina Igorevna \\ Bumbina Natalia Vyacheslavovna \\ Usol'tseva Nadezhda Vasilievna
}

\begin{abstract}
The possibility of using the predicting method based on computer modeling and subsequent calculation of molecular parameters in the original program "CMP ChemCard" to assess the ability of columnar mesophase formation by discotic, star-shaped and polycatenar organic compounds is considered. The molecular design of potential mesogens with a predictable type of mesomorphism has been carried out and individual representatives have been synthesized. The effectiveness of the application of the developed method for the search for new molecular structures of the above mentioned types, potentially capable of exhibiting columnar mesomorphism, has been substantiated.
\end{abstract}

Key words: liquid crystals, columnar mesomorphism, modeling, prediction, discotic, star-shaped, polycatenar compounds, synthesis.

Жидкие кристаллы (ЖК) играют ключевую роль при создании новых поколений перспективных наноматериалов для развития ведущих областей современных технологий $[1$, с. $331 ; 2$, с. 557; 3, с. 32]. Особый интерес для исследований и развития наноэлектроники вызывают дискотические мезогены [2, с. 557]. Однако, в последнее время привлекают внимание мезогены со звездообразным [4] и поликатенарным типом молекул, также проявляющие колончатый мезоморфизм [5, с. 1] (Рис. 1).

Активное изучение дискотических мезогенов началось сравнительно недавно - с 1977 г. [6, с. 471]. Молекулярный дизайн и синтез таких соединений является не тривиальной задачей и связан с необходимостью анализа взаимосвязи «структура - мезоморфизм» у большого числа соединений [7, с. 302]. Понимание принципов формирования жидкокристаллического состояния, поиск закономерностей проявления мезоморфных свойств в зависимости от молекулярного строения органических соединений и развитие 
различных подходов к описанию этих закономерностей сократят большие объемы материальных и временных затрат по синтезу потенциальных мезогенов.

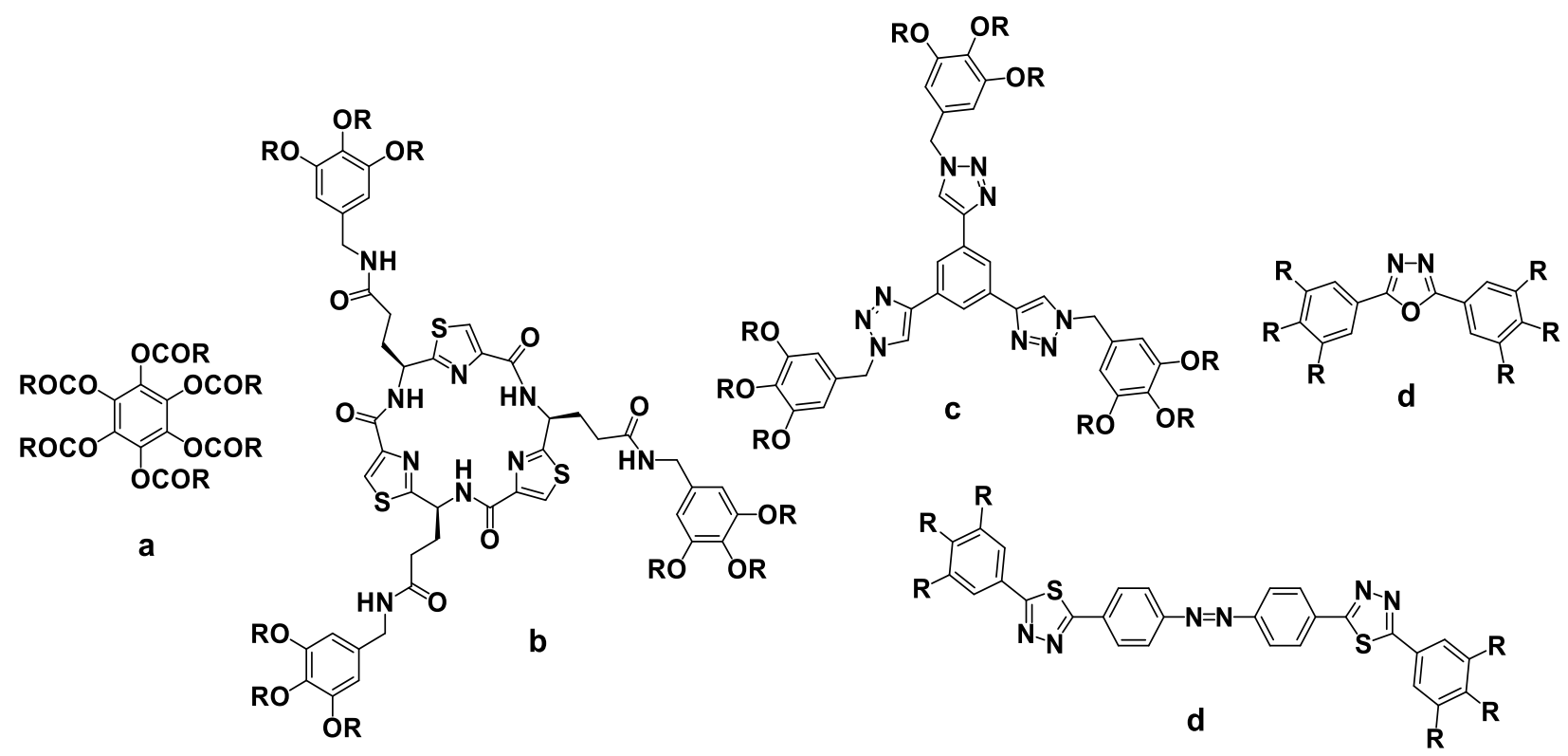

Рис. 1. Примеры гетероциклических соединений различных типов, проявляющих термотропный колончатый мезоморфизм:

а) дискотические [6, с. 471],

b) звездообразные с гибкими спейсерами [4],

c) звездообразные с жесткими спейсерами [4],

d) поликатенарные [23, c. 45$]$

Исследования в этом направлении насчитывают уже не один десяток лет, начиная с работ Майера и Заупе в 1958 г. [8, с. 564; 9, с. 822] и до настоящего времени [7, с. $302 ; 10$, с. $22 ; 11$, с. $20 ; 12$, с. 259$]$.

Цель данной работы заключается в проведении анализа эффективности применения, разработанного нами метода прогнозирования колончатого мезоморфизма применительно к органическим соединениям различной молекулярной структуры (дискотическим, звездообразным и поликатенарным).

Анализ теоретических работ по моделированию и прогнозу мезоморфизма различного типа свидетельствует о значительном прогрессе в этой области [12, с. 259; 13, с. 8854; 14, с. 2092]. Однако модели, предлагаемые большинством теорий, связаны с серьёзными вычислительными затратами, оперируют большим числом эмпирических параметров, практически не учитывают особенности молекулярного строения соединений и не всегда могут 
прогнозировать весь спектр фазовых переходов. Все это в определенной мере ограничивает их прогностическую способность и широкое применение $[10$, с. 22].

Один из методов прогноза изначально был предложен нами для дискотических соединений с целью конструирования и поиска новых мезогенных структур с колончатыми надмолекулярными упаковками $[15$, с. 1]. Этот метод позволяет осуществлять прогноз, опираясь на строение оптимизированных в программе “HyperChem" (метод $\mathrm{MM}^{+}$) единичных молекул, на основании которых рассчитываются молекулярные параметры (MP) и проводится их дальнейший анализ с использованием оригинальной программы “CMP ChemCard” (Рис. 2) [16; 17, с. 275].

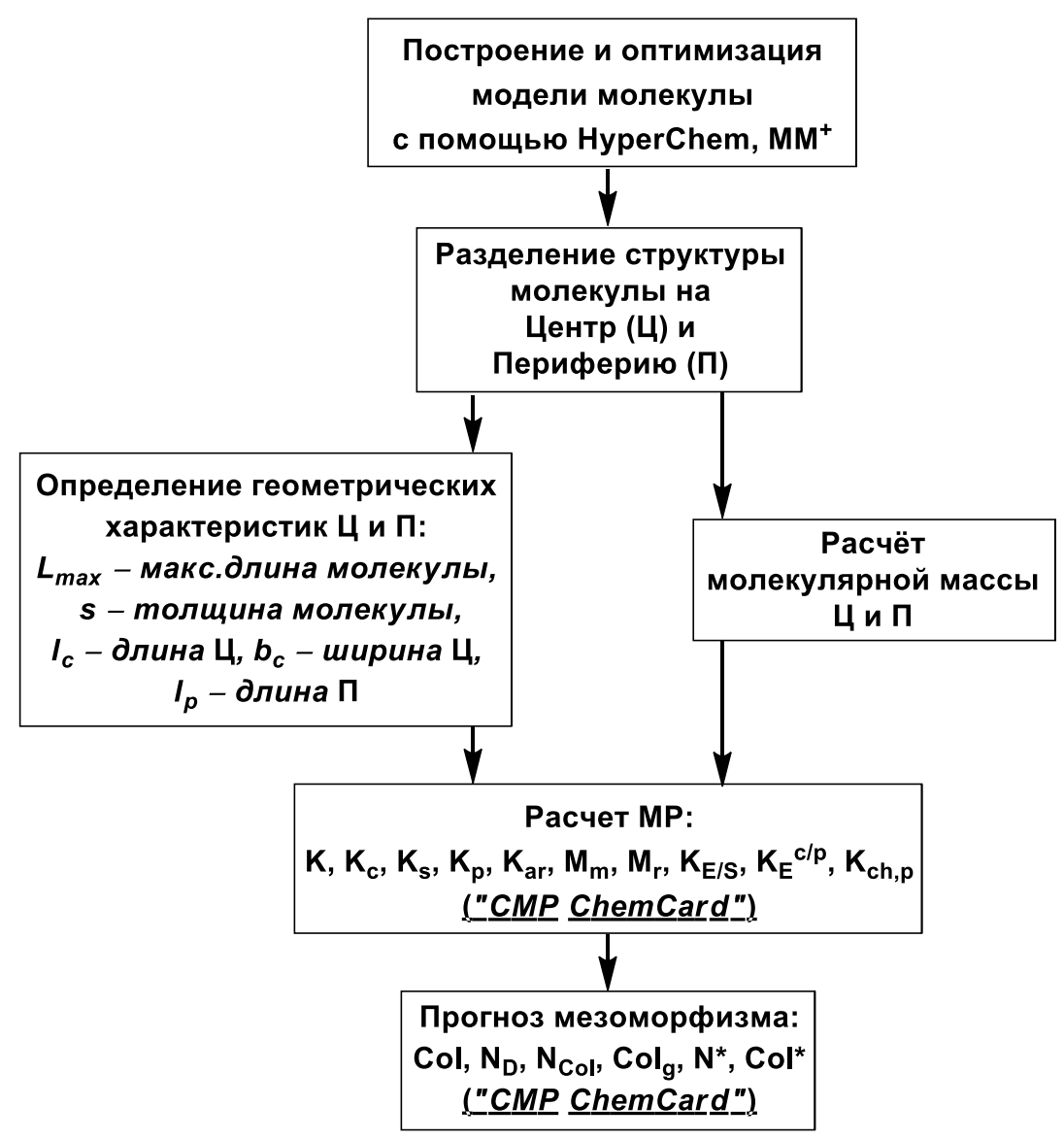

Рис. 2. Схема прогноза мезоморфизма у низкомолекулярных дискотических органических соединений с помощью программы «ChemCard» [17, c. 275].

Описание молекулярных параметров - см. в ссылках и тексте 
При создании и обосновании метода мы базировались на исследовании около 3000 соединений с дискотической формой молекул, у которых экспериментально доказано наличие или отсутствие колончатого мезоморфизма $[15$, с. 1]. Основой метода послужили следующие положения:

- необходимость соблюдения принципа: высшая иерархия (надмолекулярная организация ЖК) задается низшей (пространственной структурой молекул);

- учет взаимосвязи между температурным интервалом существования мезофазы у дискотических мезогенов и соотношением масс атомов центрального дискотического фрагмента молекулы и ее периферийных заместителей;

- необходимость введения количественной меры геометрической анизометрии молекул и их отдельных частей, определяемой из пространственных моделей единичных молекул;

- построение пространственных моделей единичных молекул с учетом пространственного расположения периферийных заместителей: углеводородные радикалы находятся в максимально вытянутой трансконформации, с чередованием над и под плоскостью центрального фрагмента;

- пространственное разделение в молекулярной структуре гидрофобных и гидрофильных молекулярных зон, т. е. необходимость количественного учета баланса сил гидрофобно/гидрофильных взаимодействий;

- учет степени окружения центрального фрагмента молекулы периферийными заместителями.

Они послужили основанием для введения количественных значений МР, которые характеризуют ту или иную молекулярную структуру с точки зрения ее способности проявлять мезофазы, типичные для дискотических мезогенов. Был определен классификационный ряд молекулярных параметров $\{1\}$, по которому можно выделить дискотические мезогены, формирующие колончатые мезофазы:

$$
\begin{gathered}
K=2.0-8.5 ; K_{c}=1.0-2.6 ; K_{p}=0.2-0.7 ; K_{s}=0.25-1.0 ; K_{a r}=0.08-0.3 ; \\
M_{m}=0.2-0.8 ; M_{r}=0.15-0.80
\end{gathered}
$$

Кроме того, в дополнение к этому ряду были введены молекулярные параметры как классификаторы для выделения мезогенов с нематическими $\left(\mathrm{N}_{\mathrm{D}}\right.$ или $\left.\mathrm{N}_{\mathrm{Col}}\right)$ мезофазами $\{1 \mathrm{a}\}$, мономезоморфных нематогенов $\{16\}$, склонных к стеклованию дискотиков $\{1 \mathrm{~B}\}$ и дискотиков с проявлением хирального мезоморфизма $\{1 \Gamma\}$ :

$$
M_{m}^{\prime}=0.9-2.3
$$




$$
\begin{array}{ll}
K_{E / S}=1.0-2.0 & \{1 \sigma\} \\
K_{E}^{c / p} \leq 2 & \{1 \mathrm{~B}\} \\
K_{\text {ch.p }}=0.03-0.25 & \{1 \Gamma\}
\end{array}
$$

Классификационный ряд $\{1\}$, классификатор $\{1 \mathrm{a}\}$ и их граничные значения, в пределах которых наиболее вероятно ожидать проявления мезоморфизма указанных типов, включены в компьютерную программу " $C M P$ ChemCard” [16]. C eе помощью осуществляется прогнозирование преимущественно колончатого мезоморфизма (с достоверностью $\geq 70 \%$ ) (Рис. 3) и поиск новых перспективных мезогенных молекулярных структур дискотической формы для дальнейшего синтеза, исследования и применения $[11$, с. $20 ; 18$, с. $1885 ; 19$, с. $20 ; 20$, с. 629$]$.

По условиям метода существенное отклонение хотя бы одного МР от граничных значений классификационного ряда $\{1\}$ свидетельствует о неспособности сконструированного соединения формировать мезофазы, типичные для дискотических мезогенов. В случае незначительного отклонения расчетных значений МР можно ожидать появления латентной (скрытой) мезофазы. Каждый из приведенных МР (Рис. 2) показывает относительный вклад отдельных частей (фрагментов) молекулы в еe способность формирования мезофаз.

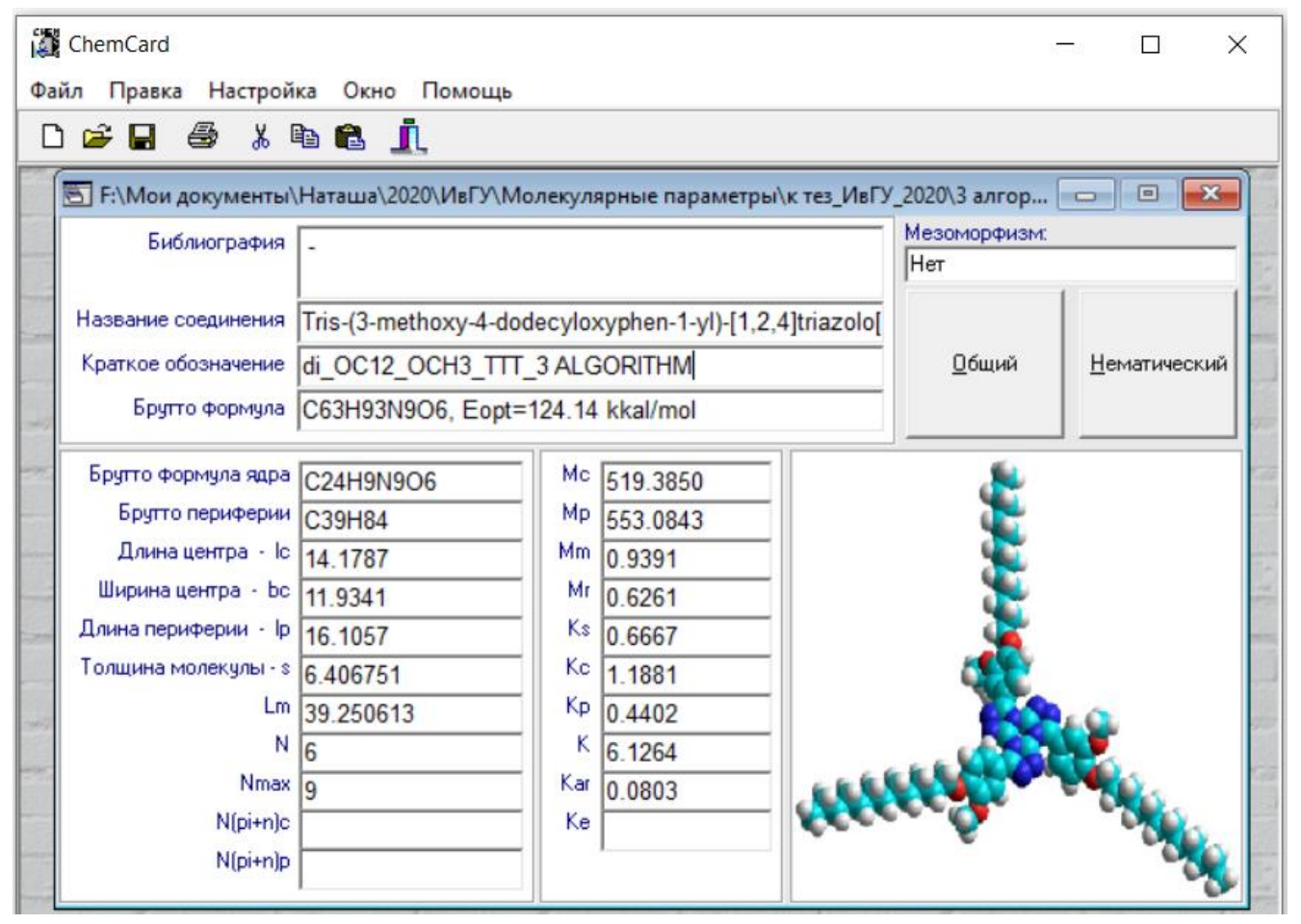

Рис. 3. Пример расчета MP в программе СMP “ChemCard" 
Так, параметры $K, K_{c}$ и $K_{p}$ являются геометрическими и характеризуют форму молекулы, симметричность формы центрального ядра и вклад длины гидрофобной части молекулы по отношению к ее полярному центру, соответственно. Параметр $K_{s}$ показывает степень замещенности центрального ядра молекулы периферийными заместителями, а параметр $K_{a r}$ указывает на плотность окружения ими центрального фрагмента. Молекулярно-массовый параметр $M_{m}$ является отношением молекулярной массы центральной части молекулы к сумме молекулярных масс периферийных заместителей, а параметр $M_{r}$ рассчитывается с учетом степени замещенности центрального фрагмента периферийными заместителями. Молекулярные параметры являются относительными величинами. Расчетные формулы можно найти в работе [21, с. $800]$, а обоснование их вывода - в [15, с. 1].

Затем данный метод был применен нами к звездообразным и поликатенарным структурам для поиска соединений, которые могут формировать Col-мезофазы [12, с. 259]. Правомерность его применения была обоснована проверкой на известных звездообразных $[12, c .259]$ и поликатенарных [23, с. 45] соединениях, для которых тип мезоморфизма установлен экспериментально. У звездообразных молекул обычно жесткий полярный центр связан с гидрофобной периферией гибкими или полугибкими спейсерами (Рис. 1), а в структуре поликатенарных соединений сочетаются элементы каламитных и дискотических молекул (Рис. 1), то есть форма их молекул отличается от классической дискотической. Поэтому в процессе работы потребовалась частичная модификация метода MP "CMP ChemCard" $[12$, с $259 ; 23$, с. 45$]$, которая не только дала возможность его использовать, но даже повысила эффективность прогноза в приложении к таким сложным структурам, как звездообразные и поликатенарные, что наглядно демонстрирует таблица 1.

Таблица 1

Модификация метода прогноза Col-мезоморфизма применительно к различным типам моделируемых структур

\begin{tabular}{|c|c|c|c|}
\hline $\begin{array}{c}\text { Тип } \\
\text { моделируемой } \\
\text { структуры }\end{array}$ & $\begin{array}{c}\text { Классификационный } \\
\text { ряд }\end{array}$ & $\begin{array}{c}\text { Вносимые } \\
\text { изменения }\end{array}$ & $\begin{array}{c}\text { Достоверность } \\
\text { прогноза, } \\
\text { \% }\end{array}$ \\
\hline & & & $\geq 70$ \\
дискотический & $\{1\}$ & Базовый & {$[7$, с. $302 ;$} \\
& & (введен впервые) & 15, с. $1 ;$ \\
& & 19, c. 20; \\
\hline
\end{tabular}




\begin{tabular}{|c|c|c|c|}
\hline звёздообразный & $\begin{array}{c}\text { Расширение ряда }\{1\} \\
\text { введением нового } \\
\text { параметра } \\
\boldsymbol{M}_{\text {Sps }}=\mathbf{0 . 1 5 - 0 . 2 5}\end{array}$ & $\begin{array}{c}\text { Вариация } \\
\text { алгоритмов } \\
\text { и модификация } \\
\text { ряда }\{1\}+ \\
\text { введение нового } \\
\text { МР }\end{array}$ & $\begin{array}{c}80-83 \\
{[12, \text { c. } 259]}\end{array}$ \\
\hline поликатенарный & 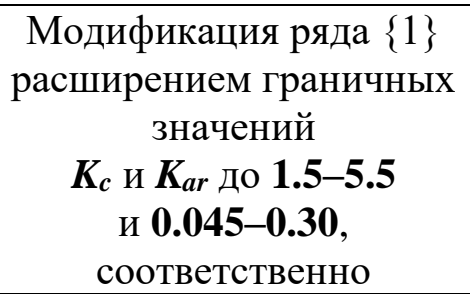 & $\begin{array}{c}\text { Вариация } \\
\text { алгоритмов и } \\
\text { модификация } \\
\text { ряда }\{1\}\end{array}$ & $\begin{array}{c}76 \\
{[23, \text { c. } 45]}\end{array}$ \\
\hline
\end{tabular}

Примечание: $\boldsymbol{M}_{\boldsymbol{S p s}}$ - молекулярно-массовый параметр, учитывающий вклад молекулярных масс гибких спейсеров в молекулярную массу молекулы в целом.

Далее на базе проведенного теоретического обоснования о применимости метода к объектам со звездообразной и поликатенарной структурами нами была поставлена задача перехода к конструированию и синтезу новых полифункциональных мезогенов с целью проверки результатов прогноза экспериментальным путем. Для этого был осуществлен молекулярный дизайн новых звездообразных (Рис. 4, соединения 1-3) и поликатенарных структур (Рис. 4, соединения 4-5) с азогруппами и фрагментами оксадиазола. По результатам выполненного прогноза несколько структур были синтезированы (Рис. 5) и их мезоморфные свойства исследованы с целью проверки результатов прогноза.

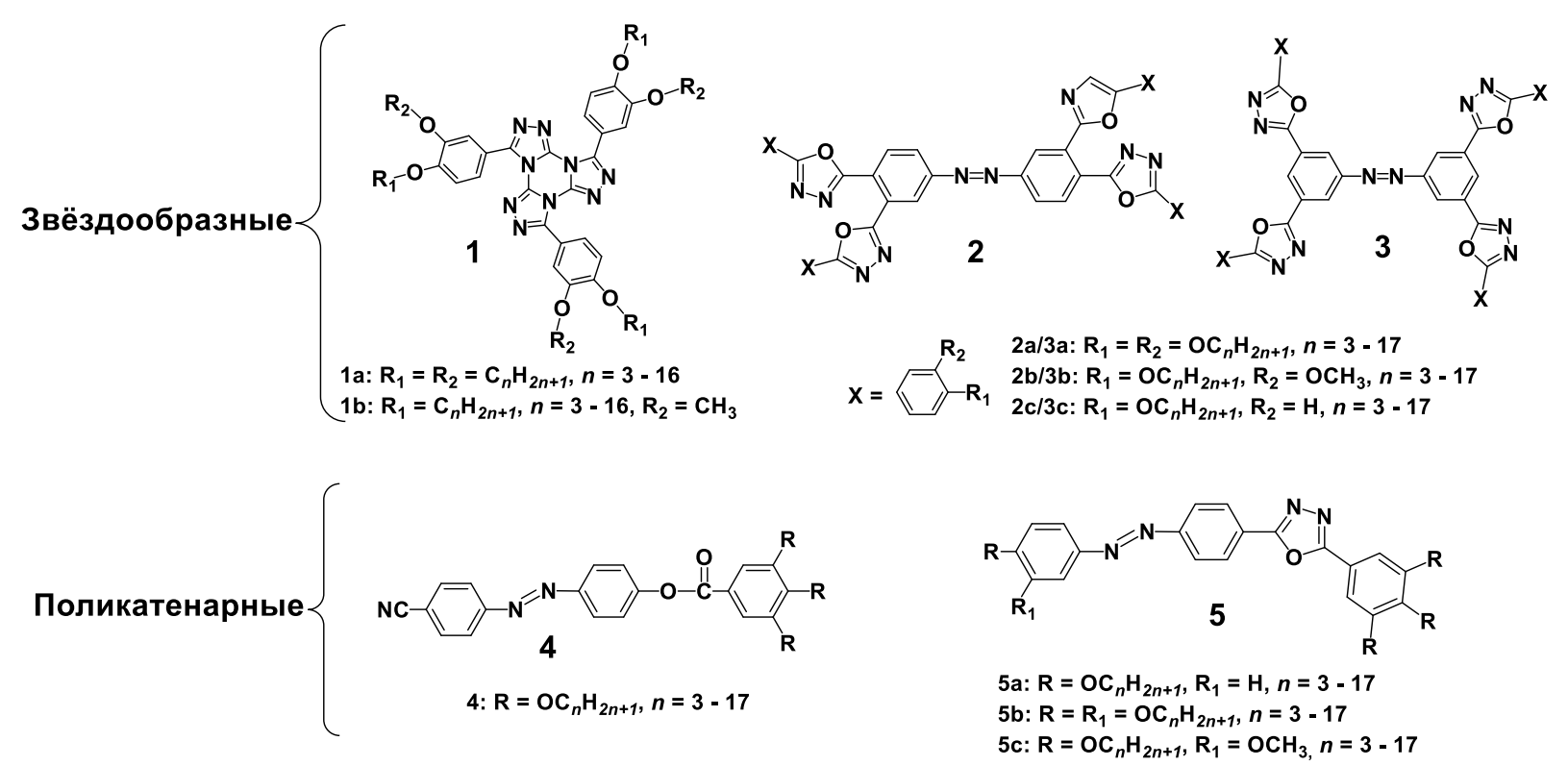

Рис. 4. Структурные формулы серий звездообразных (1-3)

и поликатенарных соединений (4-5) 
Подробные методики синтеза, очистки и идентификации веществ приведены в $[24$, с. 54; 25, с. 76]. Исследование мезоморфных свойств выполнено с помощью метода поляризационной микроскопии (Рис. 6) и дифференциальной сканирующей калориметрии (Табл. 2).

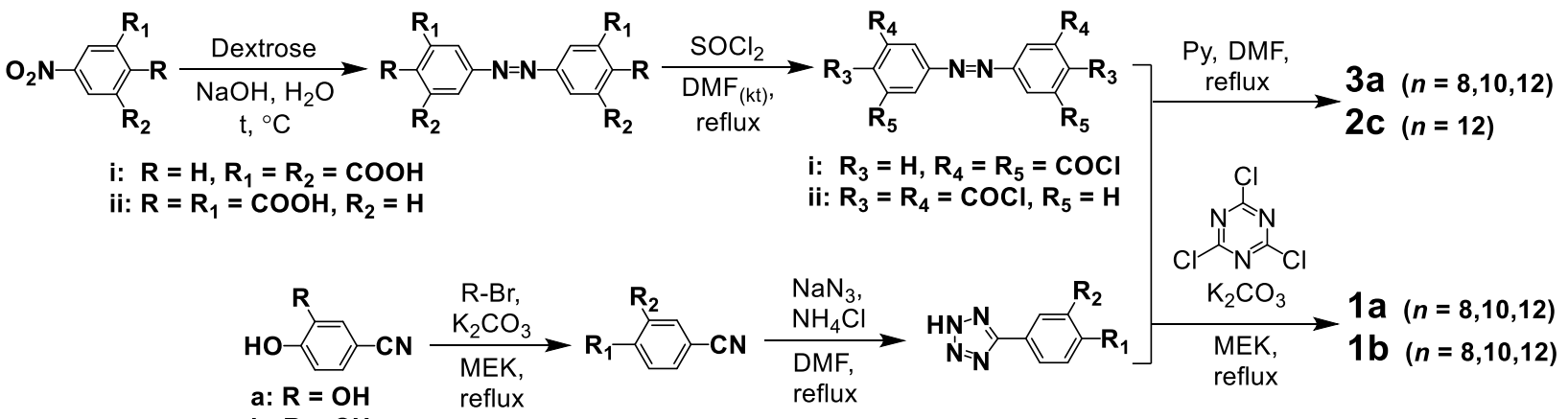

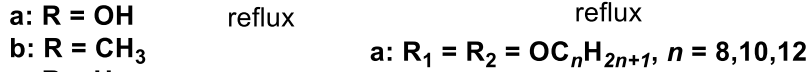

$$
\begin{aligned}
& \text { c: } R=H \quad \text { b: } R_{1}=O_{n} H_{2 n+1}, n=8,10,12 ; R_{2}=O C_{3} \\
& \text { c: } R_{2}=O C_{12} H_{25}, R_{2}=H \\
& 4\left(\mathrm{R}=\mathrm{OC}_{n} \mathrm{H}_{2 n+1}, n=8,12\right)
\end{aligned}
$$

Рис. 5. Схемы синтеза гетероциклических звездообразных 1 - 3 и поликатенарных соединений 4

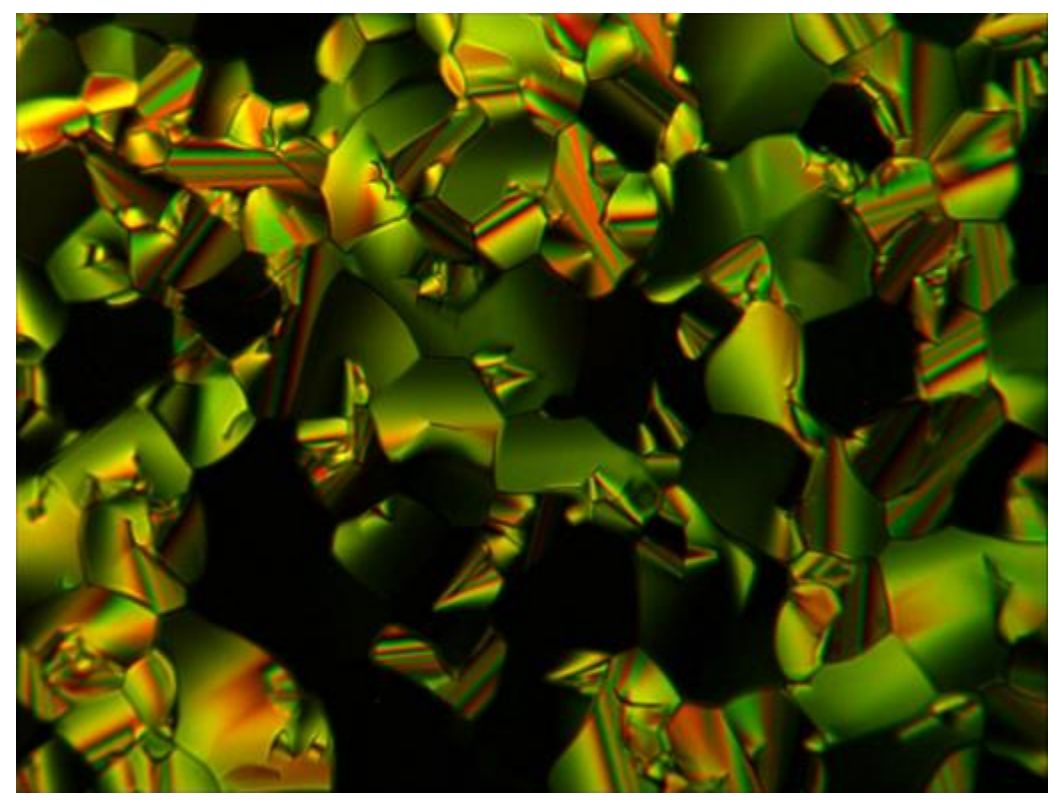

Рис. 6. Микрофотографии текстуры Col-мезофазы соединения 1a $(\boldsymbol{n}=10)$, $\mathrm{T}=202{ }^{\circ} \mathrm{C}$ при охлаждении, поляризаторы скрешены, $\times 100$ 


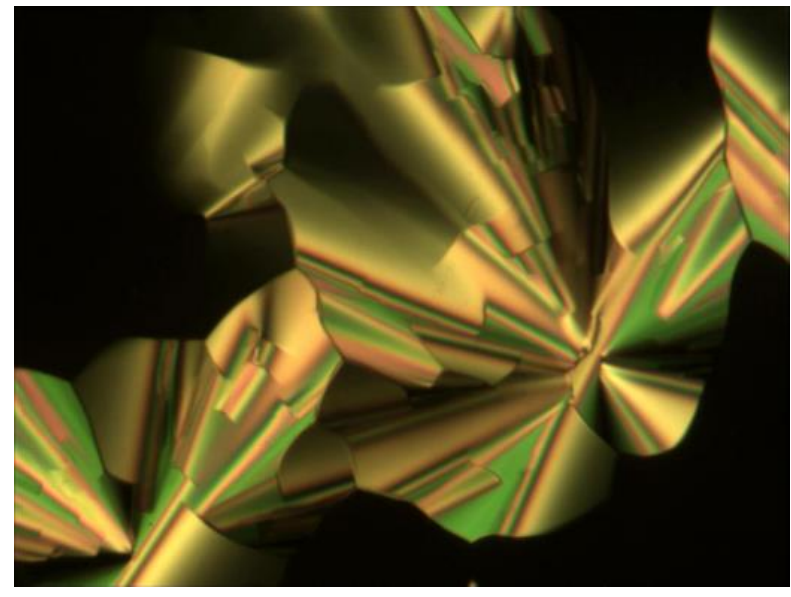

Рис. 7. Микрофотографии текстуры Col-мезофазы соединения 3а $(n=12)$, $\mathrm{T}=229{ }^{\circ} \mathrm{C}$ при охлаждении, поляризаторы скрещены, $\times 100$

Таблица 2

Данные по мезоморфизму некоторых синтезированных соединений, полученные прогностическим и экспериментальным путем

\begin{tabular}{|c|c|c|c|c|}
\hline Соединение & $\begin{array}{c}\text { Гомолог, } \\
n\end{array}$ & $\begin{array}{c}\text { Прогноз } \\
\text { Col- } \\
\text { мезоморфизма }\end{array}$ & $\begin{array}{c}\text { Температуры фазовых } \\
\text { переходов, } \\
{ }^{\circ} \mathrm{C}\end{array}$ & $\begin{array}{c}\Delta \mathrm{T}_{\text {(эксп.) }}, \\
{ }^{\circ} \mathrm{C}\end{array}$ \\
\hline \multirow{3}{*}{$1 \mathbf{a}$} & 8 & + & Cr 100.8 Col 228.0 Iso & 127 \\
\hline & 10 & + & Cr 97.2 Col 218.4 Iso & 121 \\
\hline & 12 & + & Cr 90.1 Col 205.8 Iso & 113 \\
\hline \multirow{3}{*}{ 1b } & 8 & - & Cr 130.9 Iso & 0 \\
\hline & 10 & - & Cr 117.2 Iso & 0 \\
\hline & 12 & - & Cr 106.0 Iso & 0 \\
\hline $2 \mathbf{c}$ & 12 & \pm & Cr 40 Mes 107 Iso & 67 \\
\hline \multirow{3}{*}{ 3a } & 8 & + & Cr 155 Col 265 Iso & 110 \\
\hline & 10 & + & Cr 126 Col 250 Iso & 124 \\
\hline & 12 & + & Cr 106 Col 236 Iso & 130 \\
\hline 4 & 12 & - & Cr 70 Iso & 0 \\
\hline
\end{tabular}

$\Delta \mathrm{T}_{\text {(эксп.) }}$ - диапазон существования Col-фазы. $\mathbf{C r}$ - кристаллическая фаза, Col колончатая мезофаза, Mes - вязкая мезофаза с негеометрической текстурой, вероятно колончатого типа, Iso - изотропная фаза 


\section{Заключение}

Проведен анализ модификации метода прогноза Col-мезоморфизма с помощью молекулярных параметров в программе "CMP ChemCard" и его эффективности применительно к различным типам структур: дискотическим ( $\geq$ $70 \%)$, звездообразным ( $\geq 80 \%$ и и поликатенарным ( $\geq 76 \%)$.

На базе предложенных методик осуществлен прогноз Col-мезоморфизма у 180 новых звездообразных и поликатенарных соединений с азогруппами и фрагментами оксадиазола. Из них 92 структуры показали способность к проявлению Col-мезоморфизма, у 24 соединений может наблюдаться латентный мезоморфизм. Результаты прогноза подтверждены экспериментально синтезом и исследованием мезоморфизма отдельных представителей звездообразных и поликатенарных соединений. Установлено согласие результатов прогноза с экспериментальными данными на уровне 96\%.

\section{Примечание}

Работа выполнена в рамках госзадания Минобрнауки РФ № FZZM-20200006 и частично поддержана грантом РФФИ № 19-03-00763а.

\section{Список литературы}

1. Stamatoiu O., Mirzaei J., Feng X., Hegmann T. Nanoparticles in liquid crystals and liquid crystalline nanoparticles // Liquid Crystals. Topics in Current Chemistry. Springer, Berlin, Heidelberg. - 2012. - Vol. 318. - P. 331-394.

2. Усольцева Н. В., Смирнова А. И., Казак А. В., Соцкий В. В., Лукьянов И. Ю., Галанин Н. Е., Шапошников Г. П. Наноструктурированные материалы на основе мезогенных смешанно-замещенных фталоцианинов. Глава 13 в Монографии: Органические и гибридные наноматериалы: получение и перспективы применения / под редакцией В. Ф. Разумова и М. В. Клюева. Иваново: Иван. гос. ун-т, - 2015. - С. 557-623.

3. Lapanik V. I., Lugovsky A. P., Timofeev S. N. New way to create highspeed LCD's based on the use of modified nanomaterials // Докл. БГУИР. - 2019. Vol. 7. - No 125. - P. 32-38.

4. Усольцева Н. В., Акопова О. Б., Жарникова Н. В., Смирнова А. И., Бумбина Н. В., Ковалева М. И. База данных: «Звездообразные дискотические соединения». 2017. Свид. о гос. рег. базы данных № 2017620388.

5. Weissflog W. Laterally alkyl- and aryl-substituted, swallow-tailed, and polycatenar mesogens: structural features and functionalities / Handbook of Liquid Crystals. - 2014. - Vol. 8. Set, Second Edition. Edited by J. W. Goodby, P. J. 
Collings, T. Kato, C. Tschierske, H. F. Gleeson, P. Raynes. (C) 2014 Wiley-VCH Verlag GmbH \& Co. KGaA. Published 2014 by Wiley-VCH Verlag GmbH \& Co. KGaA. P. 1-86.

6. Chandrasekhar S., Sadashiva B. K., Suresh K. A. Liquid crystals of disc-like molecules // Pramana - J. Phys. - 1977. - Vol. 9. - P. 471-480.

7. Акопова О. Б. Прогнозирование с помощью молекулярных параметров возможности формирования колончатых мезофаз и дискоидной нематики различных классов органических соединений. Глава 3 в монографии: Жидкие кристаллы: дискотические мезогены / Под. ред. Н. В. Усольцевой. Иваново: Иван. гос. ун-т, - 2004. - С. 302-411.

8. Maier W., Saupe A. Eine einfache molekulare theorie des nematischen kristallinflussigen zustandes // Z. Naturforsch. - 1958. - Bd. 13a. - No 7. - S. 564566.

9. Maier W., Saupe A. Eine einfache molekular-statistische theorie der nematischen kristallinflussigen phase 1 // Z. Naturforsch. - 1959. - Bd. 14a. - No 10. - S. 822-829.

10. Акопова О. Б., Ковалева М. И. Молекулярный дизайн и синтез звездообразных дискотических мезогенов гетероциклической природы // Жидк. крист. и их практ. использ. - 2014. - Т. 14. - № 2. - С. 22-57.

11. Акопова О. Б., Пестов С. М. Успехи в конструировании и синтезе хиральных дискотических мезогенов // Жидк. крист. и их практич. использ. 2012. - Вып. 4. - С. 20-33.

12. Акопова О. Б., Бумбина Н. В., Жарникова Н. В., Смирнова А. И., Усольцева Н. В. Прогноз, синтез и самоорганизация гетероциклических звездообразных дискотических соединений. Глава 9 в монографии: Органические и гибридные наноматериалы: получение и перспективы применения / Под ред. В. Ф. Разумова и М. В. Клюева. Иваново: Иван. гос. ун-т, - 2017. - С. 259-322.

13. Koch M., Saphiannikova M., Santer S., Guskova O. Photoisomers of azobenzene star with a flat core: theoretical insights into multiple states from DFT and MD perspective // J. Phys. Chem. B. - 2017. - Vol. 121. - No 37. - P. 88548867.

14. Said S. M., Mahmood M. S., Daud M. N., Mohd Sabri M. F., Sair, N. A. Structure-electronics relations of discotic liquid crystals from a molecular modelling perspective // Liq. Cryst. - 2016. - Vol. 43. - No 13-15. - P. 2092-2113. 
15. Акопова О. Б. Закономерности связи молекулярного строения дискотических соединений с проявлением термотропного мезоморфизма: Автореф. ... дис. д-ра хим. наук. - Иваново. 2009. - С. 1-38.

16. Акопова О. Б., Акопов Д. А. Программа для ЭВМ СМР "ChemCard”, № Гос. Рег. 2012610165, 10.01.2012.

17. Акопова О. Б., Смирнова А. И., Жарникова Н. В., Бумбина Н. В., Усольцева Н. В. Дискотические, звездообразные и поликатенарные мезогены. Анализ молекулярных параметров и прогноз мезоморфизма для направленного синтеза и создания наноматериалов нового поколения // В сборнике материалов шестого междисциплинарного научного форума с междунар. участием «Новые материалы и перспективные технологии». Москва. 23-27 ноября 2020 г. Т. 2. C. 275-278.

18. Акопова О.Б., Логачева Н. М., Баулин В. Е., Цивадзе А. Ю. Прогнозирование, синтез и исследование мезоморфизма новых окта-(бензо-15краун-5)-замещенных производных фталоцианина и его металлокомплексов Zn(II), Ni(II) // Журн. общ. химии - 2008. - Т. 78. - №11. - C. 1885-1890.

19. Акопова О. Б., Лапшин В. Б., Терентьев В. В., Богданов В. С. Карбоксилаты меди: моделирование, синтез, мезоморфизм и трибологические свойства // Жидк. крист. и их практич. использ. - 2012. - Вып. 2. - С. 20-28.

20. Знойко С. А., Акопова О.Б., Бумбина Н.В., Усольцева Н.В., Кривова А.В., Майзлиш В. Е., Шапошников Г. П. Абрамов И. Г. Нуклеофильное замещение в 4-бром-5-нитрофталодинитриле. XI. Синтез, свойства и прогноз мезоморфизма смешаннозамещенных фталоцианинов, сочетающих арилоксигруппы и бензо-триазольные фрагменты // Журн. общ. химии. - 2014. - T. 84. - № 4. - C. 629-637.

21. Usol’tseva N. V., Akopova O. B., Smirnova A. I., Kovaleva M. I., Bumbina N. V., Zharnikova N. V. Star-shaped discotic compounds with aryltetrazole and oxadiazole fragments // Phase Transitions. - 2017. - Vol. 90. - No 8. - P. 800807.

22. Акопова О. Б., Бумбина Н. В., Жарникова Н. В., Смирнова А. И., Усольцева Н. В. Звездообразные соединения с фрагментами оксадиазола. І. Влияние вариации молекулярной структуры производных азо-дифталевых кислот на проявление мезоморфизма по данным прогноза // Жидк. крист. и их практич. использ. - 2019. - Т. 19. - № 3. - С. 83-91.

23. Акопова О. Б., Смирнова А. И., Бумбина Н. В., Жарникова Н. В., Усольцева Н. В. Звездообразные соединения с фрагментами оксадиазола. III. 
Инфор-мативность разработанных для звездообразных соединений молекулярных параметров при прогнозе колончатого мезоморфизма у поликатенарных молекул // Жидк. крист. и их практич. использ. - 2020. - Т. 20. - № 2. - C. 45-54.

24. Бумбина Н. В., Акопова О. Б., Смирнова А. И., Жарникова Н. В., Усольцева Н. В. Прогноз, синтез и мезоморфизм производных азобензолтетракарбоновой кислоты с фрагментами оксадиазола // Научноисследовательская деятельность в классическом университете: традиции и инновации [Электронный ресурс] : материалы Международного научнопрактического фестиваля, Иваново, 15-29 апреля 2020 г. - Электрон. дан. Иваново: Иван. гос. ун-т, 2020. - С. 54-58.

25. Жарникова Н. В., Акопова О. Б., Смирнова А. И., Бумбина Н. В., Усольцева Н. В. Молекулярный дизайн и синтез звездообразных гетероциклов на основе тристриазолотриазина // Научно-исследовательская деятельность в классическом университете: традиции и инновации [Электронный ресурс] : материалы Международного научно-практического фестиваля, Иваново, 15-29 апреля 2020 г. - Электрон. дан. - Иваново: Иван. гос. ун-т, 2020. - С. 76-79.

(C) О.Б. Акопова, Н.В. Жарникова, А.И. Смирнова, Н.В. Бумбина, Н.В. Усольцева, 2021 